The Israeli Journal of Aquaculture - Bamidgeh, IJA_72.2020.1111879, 9 pages

CCBY-NC-ND-4.0 • https://doi.org/10.46989/001c.19005
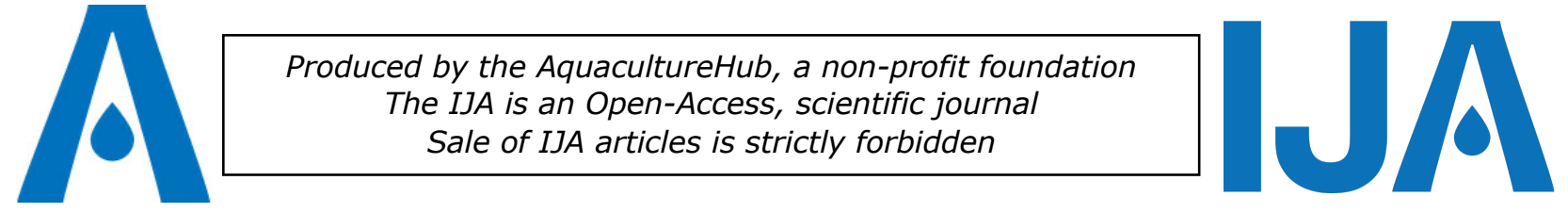

\title{
Antimicrobial property of gallic acid from Terminalia chebula Retz. effects on two pathogenic Aeromonas species isolated from cultured eel
}

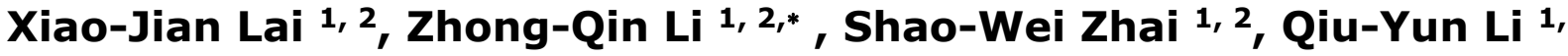 \\ 2, Xing-Long Jiang ${ }^{1,2}$ \\ ${ }^{1}$ Fisheries College, Jimei University, Xiamen, 361021, Fujian, China \\ ${ }^{2}$ Engineering Research Center of the Modern Technology for Eel Industry, Ministry of \\ Education, P. R. China, Xiamen 361021, China
}

Keywords Antibacterial components; Gallic acid; Microcalorimetry; Terminalia chebula Retz.; Aeromonas spp.

\begin{abstract}
Aeromonas spp. are prevalent pathogens in farmed eel, which induce highly infectious diseases, such as hemorrhagic septicemia and gill-rot disease. Research on the application of ethanol and water extracts from traditional Chinese herbs in controlling the diseases has increased. However, the exact antibacterial components in majority of these herbs were not well-studied. Four fractions or components were isolated from Terminalia chebula Retz. ethanol extract in our previous study. In the present study, their antibacterial effects on $A$. hydrophila and $A$. veronii were assessed using microcalorimetry. The results showed that component III (a single chemical constituent, gallic acid) had the strongest antibacterial effect compared with three other fractions. The inhibitory effect was enhanced as the concentration of component III increased, and the minimum inhibitory concentrations of component III to $A$. hydrophila and $A$. veronii were found to be $0.56 \mathrm{mg} / \mathrm{ml}$ and $0.74 \mathrm{mg} / \mathrm{ml}$ respectively. This is the first study in which the antibacterial component of $T$. chebula extract on aquatic bacteria growth was screened and determined by microcalorimetry.
\end{abstract}

* Corresponding author. Zhong Qin Li e-mail: zhqinli@jmu.edu.cn 


\section{Introduction}

It is widely recognized that Aeromonas spp. infections produce septicaemia, and ulcerative and haemorrhagic diseases in fish, causing heavy mortalities in farmed and feral fishes throughout the world (Harikrishnan and Balasundaram, 2005; Beaz-Hidalgo and Figueras, 2013). It also has been confirmed that Aeromonas spp. are prevalent pathogens in farmed eel, including $A$. hydrophila and $A$. veronii (Guo 2006). Several methods are considered to prevent and treat the disease. Researches on the application of traditional Chinese herbs in controlling diseases induced by $A$. hydrophila by dip, feed or intraperitoneal treatment has increased. These medicinal plants produced a large number of antibacterial organic chemicals and/or increased the immune response and resistance to aquaculture pathogens, including $A$. hydrophila (Harikrishnan and Balasundaram, 2005; Rao et al., 2006; Cao et al., 2012; Bilen et al., 2016; Stratev et al., 2018).

The ripened and dried fruit of Terminalia chebula Retz. is extensively used in traditional Chinese medicine. To date, however, studies on Chinese herbs including $T$. chebula have mainly focused on the pharmacological activity of its ethanol and water extracts in aquaculture (Guo and Yang, 2013). It is essential to identify the antibacterial compound from $T$. chebula fruits against $A$. hydrophila and develop an optimal extraction method to obtain high yield of the compound. In the previous study, we isolated four fractions or components from an ethanol extract of $T$. chebula by high-speed countercurrent chromatography (HSCCC). Among them, only component III contained a large amount of single chemical constituent, gallic acid (with high purity of $96.40 \%$ ), which was confirmed by electrospray ionization for mass spectrometry (ESI-MS) and high performance liquid chromatographic (HPLC) analysis. Through further purification, $17.2 \mathrm{mg}$ gallic acid was obtained from a $200 \mathrm{mg}$ ethanol extract of T. chebula ( Li et al., 2014).

In the present study, we analyzed the antibacterial activity of these isolated fractions through high-sensitivity microcalorimetry with real-time dynamic monitoring. Since growing microorganisms produce heat, microcalorimetry can be useful for characterizing the effect of drugs on their growth by measuring the heat output before and after the addition of the drug (Koenigbauer, 1994). These techniques allowed the establishment of a highly efficient isolation method and rapid and accurate activity measurement, which provide a scientific basis and reference for screening the active components of traditional Chinese medicinal extracts.

\section{Bacterial strain}

\section{Materials and Methods}

A. hydrophila B11 and $A$. veronii B59 isolated from cultivated eels were obtained from the strain library of eel pathogens (Engineering Research Center of the Modern Technology for Eel Industry, Ministry of Education, China).

\section{Preparation of $T$. chebula ethanol extract}

$T$. chebula was crushed into a 200-mesh powder using an ultrafine frozen crusher. Next, $7.5 \mathrm{~g}$ of the powder was added to $150 \mathrm{ml}$ of $60 \%$ ethanol at a powder/ liquid ratio of $1: 20 \mathrm{w} / \mathrm{v}$. Crude extraction was performed for $50 \mathrm{~min}$ in a $50^{\circ} \mathrm{C}$ ultrasonic bath. The residue was filtered, and remaining solution was placed in a multi-sample parallel evaporator for vacuum concentration in order to yield the extract, which was then stored at $4^{\circ} \mathrm{C}$ for further use.

\section{Isolation and preparation of fractions from $T$. chebula ethanol extract}

Before analytical HSCCC (TBE-20A, Tongtian), the upper and lower phases, used as the stationary and mobile phases respectively, were ultrasonically degassed for $20 \mathrm{~min}$. The solvent system of $\mathrm{n}$-hexane-ethyl acetate-methanol-water $(1: 5: 1: 5, \mathrm{v} / \mathrm{v})$ using in analytical HSCCC was optimized, and then four fractions (I, II, III, and IV) were abtained in our previous study ( $\mathrm{Li}$ et al., 2014). Subsequently, large batches of the individual fractions were isolated and prepared using preparative HSCCC (TBE-300B, Tongtian). The wavelength for UV detection was $254 \mathrm{~nm}$, and the column temperature was $25^{\circ} \mathrm{C}$. The solvent system was optimized and the effects of various parameters were tested at a 
mobile phase flow rate of $2 \mathrm{ml} / \mathrm{min}$, rotation rate of $850 \mathrm{rpm}$, and maximum injection amount of $300 \mathrm{mg}$. Under these conditions, the retention rate of the system was $63 \%$, and the isolation efficiency was better than that of analytical HSCCC (Li et al., 2014). These fractions (I, II, III, and IV) were collected, frozen, and dried respectively for further use. Component III was identified as gallic acid, with the high-purity of $96.4 \%$, by comparative HPLC analysis with standard products.

Microcalorimetry-based determination of the antibacterial effects of the isolated fractions

The inhibitory effects of the isolated fractions on $A$. hydrophila $\mathrm{B} 11$ and $A$. veronii $\mathrm{B} 59$ were examined by microcalorimetry (TAM III, Waters LC). The fractions (I, II, III, and IV) were dissolved respectively in 5\% DMSO to prepare different concentrations of the medicated solution. Under aseptic conditions, $1 \mathrm{ml} \mathrm{MH}$ broth was added to each ampoule of the bacteria to obtain a bacterial concentration of $10^{7} \mathrm{CFU} / \mathrm{ml}$. Then different concentrations of medicated solutions were added to $50 \mu \mathrm{l}$. hydrophila B11 or $A$. veronii B59 suspension in ampoules respectively. The ampoules were sealed and then placed in the microcalorimeter. The solution was cultured at $28^{\circ} \mathrm{C}$, and bacterial growth and metabolism curves $(P t-t)$ were recorded dynamically in real time.

\section{Microcalorimetric calculation method}

In the exponential growth phase of bacterial growth thermograms, two formulae $-P_{t}=$ $P_{0} \exp (k t)$ and $\ln P_{t}=\ln P_{0}+k t$ (Kong et al., 2008a)-are valid, where $P_{0}$ and $P t$ are the thermal powers of the bacteria at the starting point and at time $t$ of the exponential growth phase, respectively, while $k$ is the growth rate constant. A series of $P t-t$ data was selected from the exponential growth phase to perform linear fitting for $t$ using $\ln P t$ based on the above formulas, whereby the value of $k$ was calculated. The antibacterial effects of the medicinal extract were assessed by analyzing the linear relationship between the $k$ and extract concentration, the maximum heat production power $\left(P_{m}\right)$, and the peak time $\left(T_{m}\right)$ from the characteristic parameters represented in the bacterial thermograms.

\section{Results}

Thermogram of $A$. hydrophila B11 and A. veronii B59 treated with fractions isolated from T. chebula

Curve 1 in Figure 1 (a-d) represented the thermogram of the growth and metabolism of untreated $A$. hydrophila B11 (blank sample) at $28^{\circ} \mathrm{C}$. It was divided into five phases: delay phase, first exponential growth phase, second exponential growth phase, stabilization phase, and decay phase. The growth curves of $A$. hydrophila B11 were similar for $5 \%$ DMSO (Curve 2 in Figure 1 (a-d)). As the concentration of various medications increased, the delay phase became prolonged, the peak of the first exponential growth phase was delayed, and the second exponential growth phase disappeared and tended to decay, suggesting that the intensity of the antibacterial effects increased gradually. The growth of the pathogen was almost inhibited within $24 \mathrm{~h}$ at a component III concentration of $0.30 \mathrm{mg} / \mathrm{ml}$ (Figure 1c).

The thermogenic curves of $A$. veronii B59 growth at $28^{\circ} \mathrm{C}$ without any substance were shown in Figure $\mathbf{2}$ (curve 1 of a-d). It was divided into three phases: delay phase, exponential growth phase, and decay phase. The growth curves of $A$. veronii B59 were similar for $5 \%$ DMSO (Curve 2 of Figure $\mathbf{2}$ (a-d)). These curves changed with the increase of concentration of various medications, showing that the $T_{m}$ is suspended when the microbe growth was restrained. The growth of the pathogen was completely inhibited within $24 \mathrm{~h}$ at a component III concentration of $0.45 \mathrm{mg} / \mathrm{ml}$ (Figure 2c). 

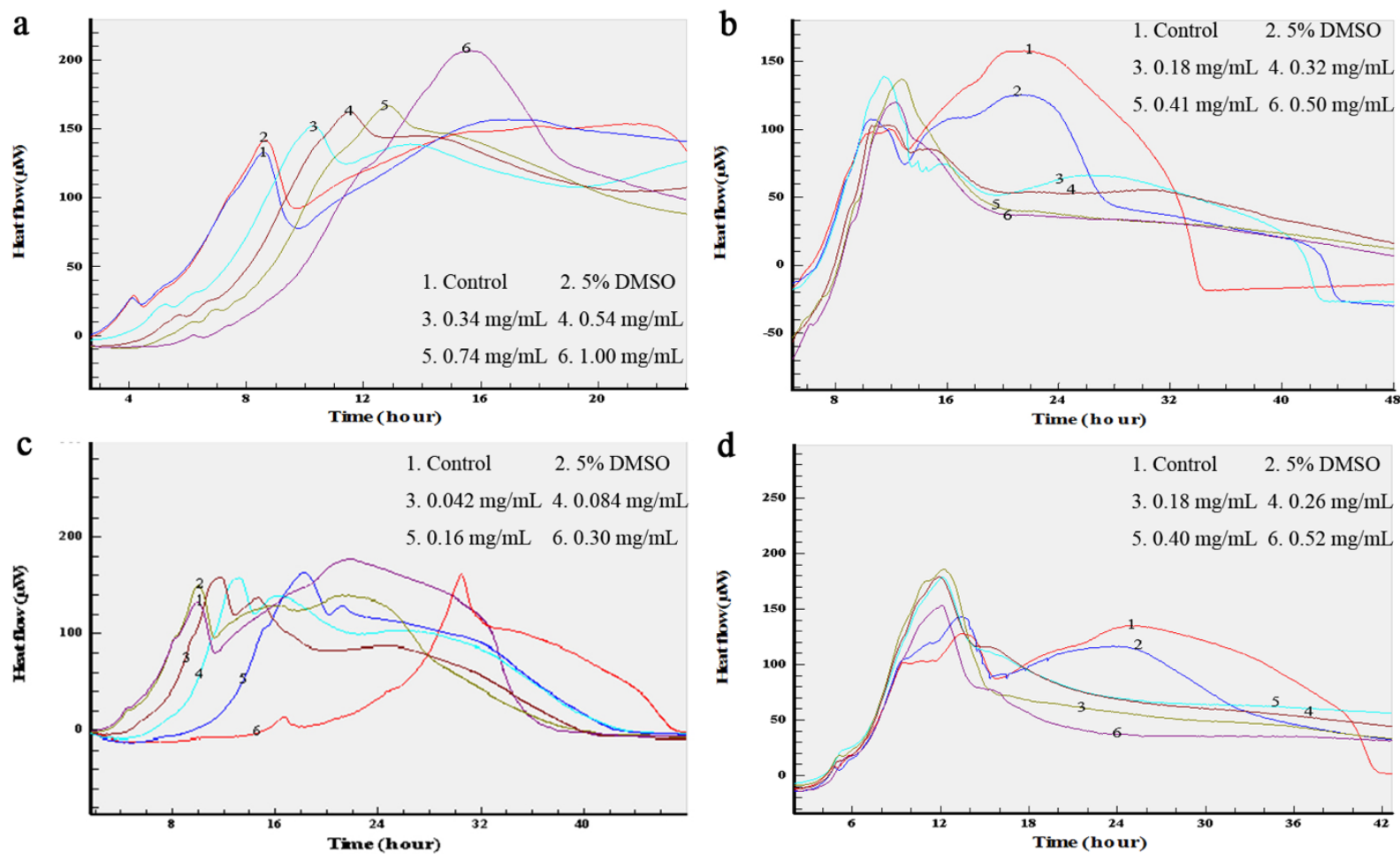

Figure 1 Power-time curves of $A$. hydrophila B11 in four fractions with different concentrations. a Fraction I. b Fraction II. c Fraction III. d Fraction IV
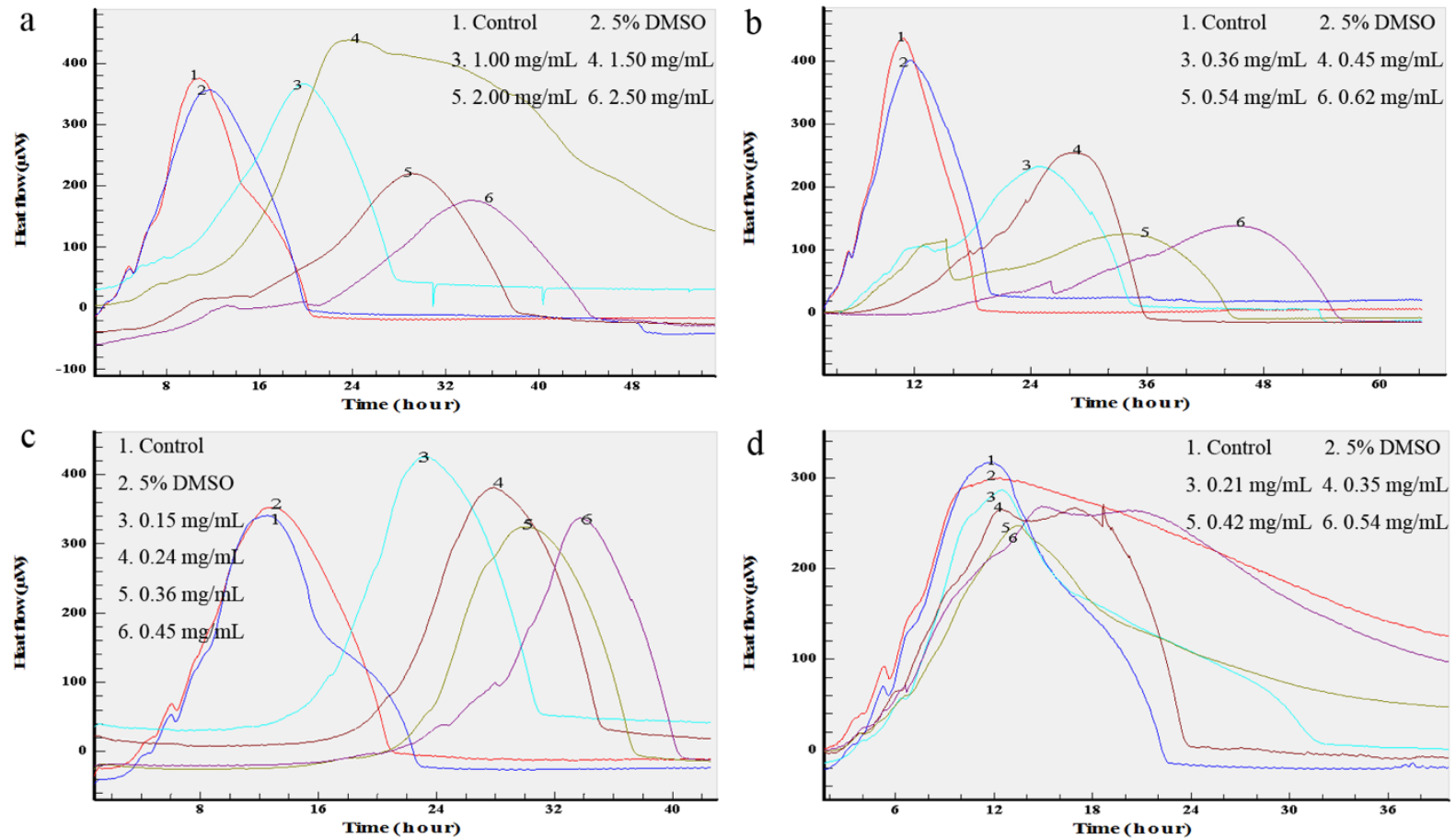

Figure 2 Power-time curves of $A$. veronii B59 in four fractions with different concentrations. a Fraction I. b Fraction II. c Fraction III. d Fraction IV 
Minimum inhibitory concentrations of isolated T. chebula fractions on A. hydrophila B11 and $A$. veronii $B 59$

Changes in the bacterial growth rate constant, $k$, was used to evaluate the antibacterial effects of fractions. The $k$ value of $A$. hydrophila B11 and $A$. veronii B59 was calculated, and a linear relationship between $k$ and the corresponding drug concentration $c$ was fitted to calculate the minimum inhibitory concentrations (MICs) of the fractions (at $k=0$ ) (Table 1). As shown in Table 1, the four fractions isolated from $T$. chebula (I, II, III, and IV) inhibited $A$. hydrophila B11 and $A$. veronii B59 growth in the order III $>$ II $>$ IV $>$ I. Component III had a lower MIC of $0.56 \mathrm{mg} / \mathrm{ml}$ or $0.74 \mathrm{mg} / \mathrm{ml}$ compared to three other fractions.

Relationship between quantitative thermokinetic parameters and concentration of component III

The $P_{t-} t$ values of the first exponential growth phase in the thermogram (Figure 1,2 ) were fitted to calculate the $k$ of $A$. hydrophila B11 and $A$. veronii B59 respectively. The relevant bio-thermokinetic parameters are listed in Table 2 . As the concentration of component III increased, the $k$ gradually decreased while the $T_{m}$ increased compared to the control.

Table 1 The correlation between the growth rate constant of A.hydrophila B11, A. veronii B59 and concentrations of the fractions separated from Terminalia chebula

\begin{tabular}{lllll}
\hline pathogen & fraction & formula & $\begin{array}{l}\text { correlation } \\
\text { coefficient }(\mathrm{R})\end{array}$ & $\begin{array}{l}\text { MIC } \\
(\mathrm{mg} / \mathrm{ml})\end{array}$ \\
\hline & I & $k=-0.0044 c+0.0077$ & 0.9873 & 1.75 \\
$\begin{array}{l}\text { A.hydrophila } \\
\text { B11 }\end{array}$ & II & $k=-0.0258 c+0.0219$ & 0.9947 & 0.85 \\
& III & $k=-0.0122 c+0.0068$ & 0.9967 & 0.56 \\
& IV & $k=-0.0014 c+0.0019$ & 0.9863 & 1.35 \\
& I & $k=-0.0014 c+0.0056$ & 0.9527 & 4.00 \\
B. veronii & II & $k=-0.0060 c+0.0055$ & 0.9945 & 0.92 \\
& III & $k=-0.0090 c+0.0067$ & 0.9837 & 0.74 \\
& IV & $k=-0.0029 c+0.0057$ & 0.9828 & 1.97
\end{tabular}

$k$, growth rate constant; $c$, concentrations of the fractions 
Table 2 The thermokinetic parameters of A.hydrophila B11 and A. veronii B59 growth in different concentrations of component III separated from Terminalia chebula

\begin{tabular}{llllll}
\hline pathogen & groups & $c(\mathrm{mg} / \mathrm{ml})$ & $T_{m} / \mathrm{min}$ & $P_{m} / \mu \mathrm{W}$ & $10^{-2} \mathrm{k} / \mathrm{min}^{-1}$ \\
\hline & 1 & 0 & 599 & 133 & 0.67 \\
& 2 & 0 & 602 & 149 & 0.69 \\
A.hydrophila & 3 & 0.042 & 706 & 158 & 0.64 \\
B11 & 4 & 0.084 & 791 & 157 & 0.56 \\
& 5 & 0.16 & 1097 & 162 & 0.49 \\
& 6 & 0.30 & 1829 & 161 & 0.32 \\
& 1 & 0 & 752 & 341 & 0.70 \\
& 2 & 0 & 781 & 352 & 0.69 \\
A. veronii & 3 & 0.15 & 1401 & 426 & 0.51 \\
& 4 & 0.24 & 1673 & 381 & 0.42 \\
& 5 & 0.36 & 1807 & 324 & 0.38 \\
& 5 & 0.45 & 2023 & 337 & 0.26
\end{tabular}

$c$, concentrations of the fractions; $T \mathrm{~m}$, the peak time at maximum heat production power; $\mathrm{Pm}$, maximum heat production power; $k$, growth rate constant

\section{Discussion}

In the present study, microcalorimetry was used to determine the inhibitory effects of $T$. chebula fractions on two Aeromonas species. The thermogenic curves of $A$. hydrophila growth affected by four fractions from $T$. chebula indicated that the component III (gallic acid) had the strongest antibacterial effect. As the concentration of component III increased, the $k$ gradually decreased while the $T_{m}$ increased. The longer the $T_{m}$ are, the stronger antibacterial activity the drugs possess. The same result was found in the restraining effect of Rheum palmatum L. on Bifidobacterium adolescentis growth (Wang et al., 2010). The MIC of component III (gallic acid) was found to be $0.56 \mathrm{mg} / \mathrm{ml}$ and 0.74 $\mathrm{mg} / \mathrm{ml}$ for A. hydrophila B11 and $A$. veronii B59 respectively. This is the first study in which the antibacterial component of $T$. chebula extract on aquatic bacteria growth was determined by microcalorimetry. The present study provided theoretical and material bases for further analysis of the pharmacological effects of $T$. chebula as well as its use in the prevention and treatment of diseases in aquatic animals.

$A$. hydrophila was extremely sensitive to the phenolic compounds from grape (Vitis vinifera L.) seed extracts and cranberry (Viburnum opulus L.) fruit extract, which containing over $500 \mathrm{mg}$ and $130 \mathrm{mg}$ gallic acid equivalent per gram extract respectively. The extracts had bactericidal activities against $A$. hydrophila at low concentrations of $1 \%$ and 5\% respectively (Baydar et al., 2006; Sagdic et al., 2006). Lu et al., (2013a) used the agar diffusion method to determine the inhibitory effect of gallic acid (reference substance) on $A$. hydrophila and found the MIC to be $0.25 \mathrm{mg} / \mathrm{ml}$. However, gallic acid purified from the flowers of Rosa chinensis Jacq. was proved to have not antibacterial activity against $A$. 
hydrophila by disc diffusion assay (Li et al., 2007). The different MIC of gallic acid probably attribute to inconsistency of the methods or antibacterial resistance. Since the need of determining the biological activity studies of drugs on microbes in high sensitivity, application of microcalorimetry, a new method, was developed (Kong et al., 2008b; Maniewska et al., 2009). Some methods, such as paper disk and agar diffusion, can also be used to assay the antibacterial activity. But the indexes are simple, and the dynamic process of bacterium growth with the effect of medicines cannot be given out in those methods (Feng et al., 2011). Therefore, microcalorimetry has an advantage over those methods. And the MIC of component III (gallic acid) against A. hydrophila determined in the present study is convincing. In addition, previous research showed Aeromonas species was resistant to different antimicrobial agents in different area and country (Cai et al., 2012). With the increase in antibiotic resistant organisms due to extensively overusing antibiotics and chemotherapy in eel farm (Lin et al., 2016), we had reasons to infer that A. hydrophila B11 and $A$. veronii B59 showed a higher antibacterial resistance.

The antioxidative, antiapoptotic, cardioprotective, neuroprotective, and anticancer properties of gallic acid and its esters, the gallates have been widely reported in human and mammals (Khadem and Marles, 2010; Kosuru et al., 2018; Zhang et al., 2018). The antibacterial activity of plant extracts containing $5.27 \%$ gallic acid is due to the disruption of the cell membrane and the leakage of cytoplasmic contents (Lu et al., 2013b). It has also been found the inhibition effects of gallic acid on the biofilm formation of human pathogenic bacteria, such as Escherichia coli, Streptococcus mutans and Pseudomonas aeruginosa (Borgesa et al., 2012; Shao et al., 2015). Gallic acid showed a great potential in being developed as a naturally sourced, nontoxic, and novel inhibitor of bacteria (Shao et al., 2015). T. chebula has definite application prospects in the prevention and treatment of $A$. hydrophila and $A$. veronii infection among aquatic animals.

\section{Acknowledgements}

We thank Prof. Vellaisamy A. L. Roy for his help with the English language of this manuscript. This study was funded by the "13th Five-Year" Demonstration Project of National Innovation and Development of Marine Economy [Grant Number: 16CZB020SF11]; China Agriculture Research System [Grant Number: CARS-46]; National Nature Science Foundation of China (Grant Number: 41806193); Fujian Provincial Department of Education Project [Grant Number: JA15260 and JT180271]; and Engineering Research Center of the Modern Technology for Eel Industry, Ministry of Education, P. R. China [Grant Number: RE201606 and RE201607].

\section{References}

Baydar NG, Sagdic O, Ozkan G, Cetin S (2006) Determination of antibacterial effects and total phenolic contents of grape (Vitis vinifera L.) seed extracts. Int J Food Sci Tech 41:799-804 doi:10.1111/j.1365-2621.2005.01095.x

Beaz-Hidalgo R, Figueras MJ (2013) Aeromonas spp. whole genomes and virulence factors implicated in fish disease. J Fish Dis 36:371-388 doi:10.1111/jfd.12025

Bilen S, Ünal S, Güvensoy H (2016) Effects of oyster mushroom (Pleurotus ostreatus) and nettle (Urtica dioica) methanolic extracts on immune responses and resistance to Aeromonas hydrophila in rainbow trout (Oncorhynchus mykiss). Aquaculture 454:90-94 doi: $10.1016 / j$.aquaculture.2015.12.010

Borges A, Saavedra MJ, Simões M (2012) The activity of ferulic and gallic acids in biofilm prevention and control of pathogenic bacteria. Biofouling 28:755-767

doi:10.1080/08927014.2012.706751

Cai SH, Wu ZH, Jian JC, Lu YS, Tang JF (2012) Characterization of pathogenic Aeromonas veronii $b v$. veronii associated with ulcerative syndrome from Chinese longsnout catfish (Leiocassis longirostris Gunther). Braz J Microbiol 43:382-388

Cao H, Xia W, Zhang S, He S, Wei R, Lu L, Yang X (2012) Saprolegnia pathogen from pengze crucian carp (Carassius auratus var. Pengze) eggs and its control with traditional Chinese herb. Isr J Aquacult-Bamid 64: 1-7 doi:10.3354/aei00039 
Feng X, Yan D, Zhao KJ, Luo JY, Ren YS, Kong WJ, Han YM, Xiao XH (2011) Applications of microcalorimetry in the antibacterial activity evaluation of various Rhizoma coptidis. Pharm Biol 49:348-353 doi: 10.3109/13880209.2010.523428

Guo SL (2006) The pathogenic bacteria indentification and correlative immune studies in eels. PhD dissertation, Institute of Hydrobiology, Chinese Academy of Sciences, WuHan, China (in Chinese)

Guo J, Yang HL (2013) Study of the effects of extracts of Terminalia chebula Retz. and their potential. China J Pathog Biol 8:89-90 doi:10.13350/j.cjpb.2013.01.010

Harikrishnan R, Balasundaram C (2005) Modern trends in Aeromonas hydrophila disease management with fish. Rev Fish Sci 13:281-320 doi:10.1080/10641260500320845 Khadem S, Marles RJ (2010) Monocyclic phenolic acids; hydroxy- and polyhydroxybenzoic acids: Occurrence and recent bioactivity studies. Molecules 15:7985-8005 doi: $10.3390 /$ molecules 15117985

Koenigbauer MJ (1994) Pharmaceutical applications of microcalorimetry. Pharm ResDordr 11:777-783 doi: 10.1023/A:1018957103417

Kong WJ, Zhao YL, Shan LM, Xiao XH, Guo WY (2008a) Preliminary searching for extraction technology and bioactive parts of Radix isatidis based on microcalorimetry. Acta Chim Sinica 66:1111-1116 (in Chinese)

Kong WJ, Zhao YL, Shan LM, Xiao XH, Guo WY (2008b) Thermochemical studies on the quantity-antibacterial effect relationship of four organic acids from Radix isatidison on Escherichia coli growth. Biol Pharm Bull 31:1301-1305 doi:10.1248/bpb.31.1301

Kosuru RY, Roy A, Das SK, Bera S (2018) Gallic acid and gallates in human health and disease: Do mitochondria hold the key to success? Molecul Nutr Food Res 62:1-10 doi: $10.1002 / \mathrm{mnfr} .201700699$

Li AJ, Chen JX, Zhu WM, Jiang T, Zhang XH, Gu QQ (2007) Antibacterial activity of gallic acid from the flowers of Rosa chinensis Jacq. against fish pathogens. Aquac Res 38:1110-1112 doi:10.1111/j.1365-2109.2007.01745.x

Li ZQ, Li QY, Jiang XL, Zhang K, Guan RZ (2014) Isolation and preparation of gallic acid from Terminalia chebula Retz. with high speed countercurrent chromatography. Chin J Chromatogr 32:1404-1408 (in Chinese) doi:10.3724/SP.J.1123.2014.07025

Lin M, Wu XM, Yan QP, Ma Y, Huang LX, Qin YX, Xu XJ (2016) Incidence of antimicrobialresistance genes andintegrons in antibiotic resistance bacteria isolated from eels and farmingwater. Dis Aquat Organ 120:115-123 doi:10.3354/dao03013

Lu J, Wang ZN, Chen R, Guan S (2013a) In vitro antibacterial activity of several Chinese medicine monomers and antibiotics on Aeromonas hydrophila and Aeromonas sobria. Acta Hydrobiologica Sinica 37:1128-1132 (in Chinese) doi:10.7541/2013.153

Lu CX, Luo XL, Luo RF, Chen X, Xing LJ, Tang ZG, Li HM (2013b) Assessment of antibacterial properties and the active ingredient of plant extracts and its effect on the performance of crucian carp (Carassius auratus gibelio var. E'erqisi, Bloch). J Sci Food Agr 93:902-909 doi:10.1002/jsfa.5823

Rao YV, Das BK, Jyotyrmayee P, Chakrabarti R (2006) Effect of Achyranthes aspera on the immunity and survival of Labeo rohita infected with Aeromonas hydrophila. Fish and Shellfish Immunol 20:263-273 doi:10.1016/j.fsi.2005.04.006

Sagdic O, Aksoy A, Ozkan G (2006) Evaluation of the antibacterial and antioxidant potentials of cranberry (gilaburu, Viburnum opulus L.) fruit extract. Acta Aliment Hung 35:487-492 doi:10.1556/AAlim.35.2006.4.12

Shao DY, Li J, Tang RH, Liu L, Shi JL, Huang QS, Yang H (2015) Inhibition of gallic acid on the growth and biofilm formation of Escherichia coli and Streptococcus mutans. J Food Sci 80:M1299-M1305 doi:10.1111/1750-3841.12902

Stratev D, Zhelyazkov G, Noundou XS, Krause RWM (2018) Beneficial effects of medicinal plants in fish diseases. Aquacult Int 26:289-308 doi:10.1007/s10499-017-0219-X Wang J, Zhao H, Kong W, Jin C, Zhao Y, Qu Y, Xiao X (2010) Microcalorimetric assay on the antimicrobial property of five hydroxyanthraquinone derivatives in rhubarb (Rheum palmatum L.) to Bifidobacterium adolescentis. Phytomedicine 17:684-689 doi:10.1016/j.phymed.2009.10.009 
Zhang YY, Liu XH, Gao ST, Qian K, Liu QS, Yin XY (2018) Research on the neuroprotective compounds in Terminalia chebula Retz extracts in-vivo by UPLC-QTOF-MS. Acta Chromatogr 30:169-174 doi: 10.1556/1326.2017.00147 